\title{
Diffuse neurofibrillary tangles with calcification: a new presenile dementia
}

\author{
Kenji Kosaka
}

\begin{abstract}
The term "diffuse neurofibrillary tangles with calcification" (DNTC) is proposed for a new form of presenile dementia. It is characterised by slowly progressive cortical dementia in the presenium, localised temporal or temporofrontal lobar atrophy, numerous neurofibrillary tangles widespread in the cerebral cortex, and pronounced calcareous deposits; 16 cases of DNTC, have been reported.
\end{abstract}

$(尹$ Neurol Neurosurg Psychiatry 1994;57:594-596)

Alzheimer's disease and Pick's disease are representative presenile dementias. Cases with unclassifiable presenile dementias have also been reported. Diffuse Lewy body disease, ${ }^{1}$ which is now considered as a disease entity, was one of them.

We wish to propose the nomenclature "diffuse neurofibrillary tangles with calcification (DNTC)" as a new presenile dementia. In 1973 we reported an interesting case with unclassifiable presenile dementia. ${ }^{2}$ Recently, we found two similar cases.

Psychiatry, Yokohama City University School of Medicine, 3-9 Fukuura, Kanazawaku Yokohama, Japan K Kosaka

Correspondence to Dr K Kosaka.

Received 11 January 1993 and in final revised form 11 May 1993 .

Accepted 9 August 1993

Figure 1 CT scan showing a bilateral frontotemporal atrophy with pallidal calcification (case 2). sion, dementia progressed, followed by mild parkinsonism and pyramidal signs. She died about seven years after onset of the disease. Clinical diagnosis was unclassifiable presenile dementia.

\section{CASE $2^{3}$}

A 55-year-old woman became forgetful. After that, dementia progressed slowly. At the age of 71, dementia was profound. Oral tendency also occurred. The patient became apallic and died at the age of 79. A CT scan showed a symmetrical localised atrophy of the temporal and frontal lobes with pallidal calcification (fig 1). Clinical diagnosis was Alzheimer's disease with Binswanger's disease.

\section{CASE $3^{4}$}

A 50-year-old woman was admitted with dementia and personality change, which had continued since the age of 46 . Muscle rigidity, gait disturbance, and bilateral pyramidal signs were also detected. Dementia progressed gradually. She became bedridden at the age of 53. Primitive reflexes, paratonic rigidity, flexion posture, and myoclonus-like involuntary movements developed. At the age of 65 , she became apallic with tetraplegia in flexion. Death occurred 22 years after onset. A CT scan revealed a temporal and frontal atrophy with pallidal calcification. Clinical diagnosis was unclassifiable presenile dementia.

The neuropathological findings of these three cases were characterised by (a) localised brain atrophy (temporal atrophy in case 1 and temporofrontal atrophy in cases 2 and 3); (b) numerous neurofibrillary tangles widespread in the cerebral cortex (fig 2), the distribution

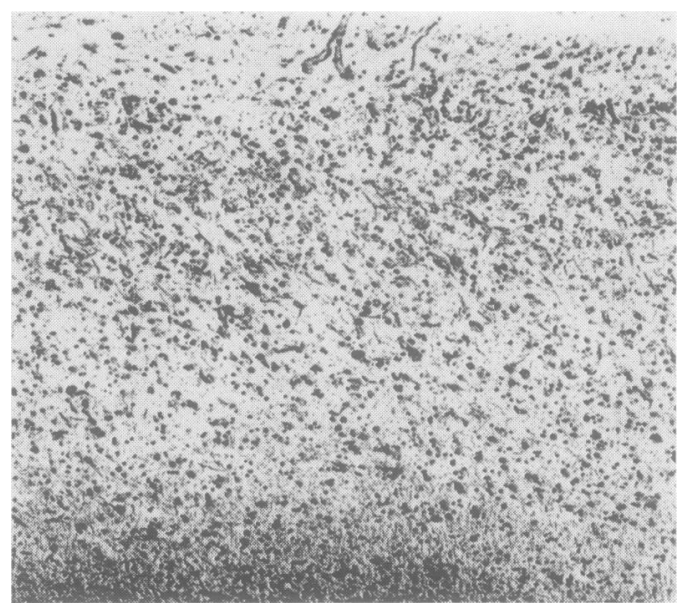

Figure 2 Numerous neurofibrillary tangles in the temporal cortex (case 2; originally Bodian stain $\times 350$ ). 
Table Reported cases with "diffuse neurofibrillary tangles with calcification (DNTC)"

\begin{tabular}{|c|c|c|c|c|c|c|c|c|}
\hline Reference & $\begin{array}{l}\text { Age at } \\
\text { death }(y)\end{array}$ & $\begin{array}{l}\text { Age at } \\
\text { onset }(y)\end{array}$ & Sex & Duration (y) & $\begin{array}{l}\text { Clinical } \\
\text { diagnosis }\end{array}$ & $\begin{array}{l}\text { Brain } \\
\text { weight (g) }\end{array}$ & $\begin{array}{l}\text { Localised } \\
\text { atrophy }\end{array}$ & Remarks \\
\hline $\begin{array}{r}5 \\
6 \\
2 \\
7 \\
8 \\
9 \\
10 \\
11 \\
3 \\
4 \\
12 \\
13 \\
13 \\
13 \\
13 \\
13\end{array}$ & $\begin{array}{l}59 \\
62 \\
54 \\
57 \\
48 \\
56 \\
49 \\
79 \\
79 \\
68 \\
67 \\
59 \\
57 \\
56 \\
64 \\
72\end{array}$ & $\begin{array}{l}48 \\
57 \\
47 \\
53 \\
45 \\
46 \\
42 \\
68 \\
55 \\
46 \\
47 \\
51 \\
50 \\
52 \\
56 \\
64\end{array}$ & $\begin{array}{l}F \\
F \\
F \\
M \\
F \\
M \\
M \\
F \\
F \\
F \\
F \\
F \\
F \\
M \\
F \\
F\end{array}$ & $\begin{array}{r}11 \\
5 \\
7 \\
4 \\
3 \\
10 \\
7 \\
11 \\
24 \\
22 \\
20 \\
8 \\
8 \\
4 \\
8 \\
8\end{array}$ & $\begin{array}{l}\text { PD } \\
\text { AD? } \\
\text { PreD } \\
\text { AD } \\
\text { AD } \\
\text { PD } \\
\text { PD } \\
? \\
\text { AD + Bins } \\
\text { PreD } \\
? \\
\text { PreD } \\
\text { AD } \\
\text { PD } \\
\text { PreD } \\
?\end{array}$ & $\begin{array}{r}1100 \\
1090 \\
1170 \\
1030 \\
1000 \\
1040 \\
1090 \\
720 \\
920 \\
850 \\
915 \\
1140 \\
1050 \\
1260 \\
1000 \\
970\end{array}$ & $\begin{array}{l}\text { T, I, Fcon }(\mathrm{R}<\mathrm{L}) \\
\mathrm{T}, \mathrm{I}>\mathrm{F} \\
\mathrm{T}>>\text { Forb }(\mathrm{R}>\mathrm{L}) \\
\mathrm{T}, \mathrm{I}, \text { Forb }(\mathrm{R}<\mathrm{L}) \\
\mathrm{T}, \mathrm{F} \\
\mathrm{T}, \mathrm{F} \\
\mathrm{T}>\mathrm{F} \\
\mathrm{T}>\mathrm{F} \\
\mathrm{T}>\mathrm{Fcon} \\
\mathrm{T}, \mathrm{F} \\
\mathrm{T}, \mathrm{F} \\
\mathrm{T}(\mathrm{R}<\mathrm{L}) \\
\mathrm{T}, \mathrm{F} \\
\mathrm{T}, \text { Forb }(\mathrm{R}<\mathrm{L}) \\
\mathrm{T}, \mathrm{T} \\
\mathrm{T}, \mathrm{F}\end{array}$ & $\begin{array}{l}\text { Case } 2 \\
\text { Case } 3\end{array}$ \\
\hline Mean & $61 \cdot 6$ & $51 \cdot 7$ & & 9.9 & & $1021 \cdot 6$ & & \\
\hline
\end{tabular}

$\mathrm{PD}=$ Pick's disease $\mathrm{AD}=$ Alzheimer's disease Pre $\mathrm{D}=$ presenile dementia; Bins = Binswanger encephalopathy; $\mathrm{T}=$ temporal lobe; $\mathrm{F}=$ frontal lobe; $\mathrm{I}=$ insule; $\mathrm{Fcon}=$ frontal convexity; Forb $=$ frontal orbita; $\mathrm{R}=$ right side; $\mathrm{L}=$ left side

of which was similar to that in typical presenile Alzheimer's disease; (c) many neuropil threads in the cerebral cortex, where neurofibrillary tangles were pronounced; $(d)$ severe neuronal loss and astrocytosis in the atrophied cortex; (e) absence of senile plaques; and $(f)$ pronounced calcareous deposits of the Fahr type.

\section{Discussion}

To our knowledge, 16 cases of DNTC, ${ }^{2-13}$ including our three, have been reported so far (table). Recently, Shibayama et al ${ }^{13}$ reported five cases of DNTC under the title of "nonAlzheimer's non-Pick's dementia with Fahr's syndrome". All cases, except one reported by Tariska, ${ }^{6}$ are Japanese. Out of 16 cases, four were men and 12 were women. The mean age at onset was 51.7 (range 42-68) years. The main clinical symptom was progressive cortical dementia, followed by various psychiatric and neurological symptoms. Disturbances of verbal function such as amnestic aphasia, sensory aphasia, and "stehende Redensarten" (a kind of palilalia) were often present. Personality changes were also commonly seen. Lack of spontaneity, loss of initiative, and apathy were pronounced in some cases, whereas uncontrollable behaviour and restlessness were predominant in others. Parkinsonism was the most frequent neurological feature. Occasional oral tendency occurred. Rare pyramidal signs were detected. At the terminal stage, apallic syndrome with primitive reflexes and tetraplegia in flexion occurred. The mean age at death was 61.6 (range 48-79) years. Total duration of illness ranged from three to 24 (mean 9.9) years. CT scans showed a localised temporal or temporofrontal atrophy with pronounced pallidal calcification. The diagnosis of DNTC is possible, when these clinical features are considered.

The most important neuropathological feature is temporal or temporofrontal lobar atrophy with numerous neurofibrillary tangles widespread in the cerebral cortex. Temporal or temporofrontal atrophy is characteristic of Pick's disease. The distribution of the temporal atrophy in DNTC, however, is different from that of Pick's disease in that the hippocampus and the superior temporal gyrus are also affected in DNTC. Also, no Pick's bodies are found. On the other hand, the wide distribution of cortical neurofibrillary tangles is one of the important hallmarks of Alzheimer's disease. As mentioned, the distribution pattern of neurofibrillary tangles in DNTC is similar to that in Alzheimer's disease. Very few senile plaques or pre-amyloid deposits are, however, found in DNTC, even when immunostaining for $\beta$-protein is used. Thus DNTC can be distinguished from Pick's disease and Alzheimer's disease. Some necropsied cases without Pick's disease but with circumscribed lobar atrophy have been reported. ${ }^{14-19}$ Some of them ${ }^{14-16}$ also had pathological findings of Alzheimer's disease. According to our clinicopathological experiences, most cases of presenile Alzheimer's disease with a longlasting apallic state at the terminal stage have such a circumscribed lobar atrophy. The possibility that these cases have both Alzheimer's and Pick's disease was previously discussed. Such cases should, however, now be diagnosed as Alzheimer's disease, as the pathological features expected for circumscribed atrophy are consistent with Alzheimer's disease and the pattern of the lobar atrophy is different from that of Pick's disease. On the other hand, rare cases $^{17-19}$ with frontal or frontotempolal lobar atrophy could be diagnosed as having the two diseases, as they had the pathological characteristics of both. Recently, frontal lobe degeneration of a nonAlzheimer type was considered. ${ }^{20}$ It was, however, different from DNTC in that the cortical pathology in DNTC is very severe and full of neurofibrillary tangles.

The presence of numerous neurofibrillary tangles is also an important pathological hallmark of dementia pugilistica, parkinsonismdementia complex of Guam(lytico-boding), progressive supranuclear palsy, and postencephalitic parkinsonism. From the clinical viewpoint, DNTC differs from these diseases in that progressive cortical dementia is the first and primary symptom. Also, the distribution of neurofibrillary tangles in 
DNTC is distinctive in that their preferential site is the cerebral cortex, although a few are found in some subcortical nuclei with a similar distribution to that of subcortical neurofibrillary tangles in Alzheimer's disease. Calcification of the Fahr type is also characteristic of DNTC.

Thus DNTC does not conform to any hitherto known disorders. As mentioned, most cases of DNTC have been reported in Japan but there might be more cases in American and European countries. Although cases with diffuse Lewy body disease were initially reported almost exclusively in Japan, cases have been reported in America and Europe $^{1}$ since we pointed out that diffuse Lewy body disease would have been overlooked there. ${ }^{21}$ Therefore, American and European clinicians and neuropathologists should be aware of the entity of DNTC.

1 Kosaka K. Diffuse Lewy body disease in Japan. 7 Neurol 1990;237:197-204.

2 Kosaka K, Shibayama N, Kobayashi H, et al. An autopsy case with unclassifiable presenile dementia. Psychiat Neurol fpn 1973;75:18-35. (In Japanese.)

3 Makino Y, Mizukami K, Kosaka K, et al. An autopsy case of atypical presenile dementia with atrophy of the temporal lobes, neurofibrillary tangles and Fahr disease. $\jmath_{p n} \tilde{f} \mathrm{Clin}$ Psychiatry 1990;19:529-34. (In Japanese.)

4 Fujishima T, Kase H, Kosaka K, et al. An autopsy case of atypical presenile dementia. 33rd Annual Meeting of fapanese Neuropathology Association, Niigata, 1992 (Abstract in Japanese.)

5 Ando S, Okaniwa T, Tachibana $M$, et al. An autopsy case with Pick's disease. Adv Neurol 1965;9:181-2. (Abstract in Japanese.)

6 Tariska I. Circumscribed cerebral atrophy in Alzheimer's disease. A pathological study. In: Wolstenholme GEW,
O'Connor M, eds. Alzheimer's disease. London: Churchill, 1970;51-73.

7 Miyoshi K, Kamiya S. A case of presenile dementia with neurofibrillary tangles and circumscribed front-tempora atrophy. Clin Neurol 1975;15:827-33. (In Japanese.)

8 Kuroda S, Shomori A, Tateishi J. An autopsy case of atyp ical Alzheimer's disease. Brain Nerve 1976;28:389-95. (In Japanese.)

9 Ishino H, Morisada A. An autopsy case of Pick's disease with numerous neurofibrillary tangles. Clin Neurol 1979;19:197-203 (In Japanese.)

10 Ishino H, Sudo K, Imaoka N, et al. A case of Pick's disease with sensory aphasia and neurofibrillary tangles. with sensory aphasia and neurofibrillary

11 Goban $\mathrm{Y}$, Yamanouchi $\mathrm{H}$, Tohgi $\mathrm{H}$, et al. An autopsy case of atypical senile dementia with multiple cerebral infarction and diffuse pseudo-calcification. Neurol Med tion and diffuse pseudo-calcing

12 Nakayama $\mathrm{H}$, Uesugi $\mathrm{H}$, Ando $\mathrm{S}$, et al. An autopsy case of atypical dementia showing numerous neurofibrillary tangles and severe calcification. 33rd Annual Meeting of fapanese Neuropathology Association, Niigata, 1992 (Abstract in Japanese.)

13 Shibayama H, Kobayashi H. Nakagawa M, et al. NonAlzheimer non-Pick dementia with Fahr's syndrome. Clin Neuropathol 1992;11:237-50.

14 Rothschild D, Kasanin J. Clinicopathologic study of Alzheimer's disease. Arch Neurol Psychiatry 1936;36: 293-321.

15 Liebers $M$. Alzheimersche Krankheit mit Pickscher Atrophie der Stirnlappen. Arch Psychiatr Nervenkrankh 1939;109:363-70.

16 Seitelberger F, Jellinger K. Umschriebene Grosshimatrophe bei Alzheimerscher Krankheit. Dtsch Z Nervenheilk 1958;178:365-79.

17 Berlin L. Presenile sclerosis (Alzheimer's disease) with features resembling Pick's disease. Arch Neurol Psychiatry tures resembling

18 Neumann MA. Pick's disease. $f$ Neuropathol Exp Neurol $1949 ; 8: 255-82$

19 Oyanagi S, Maeda T, Ikuta F, et al. An autopsy case of atypical presenile dementia with morphological features of Alzheimer's disease and Pick's disease. Psychiatry Neurol fpn 1975;77:19-27.

20 Brun A. Frontal lobe degeneration of non-Alzheimer type. I. Neuropathology. Arch Gerontol Geriatr 1987;6: 193-207.

21 Kosaka K, Yoshimura M, Ikeda K, et al. Diffuse type of Lewy body disease. A progressive dementia with numerous cortical Lewy bodies and senile changes of various degree. A new disease entity? Clin Neuropathol 1984;3: 185-92. 